\title{
Reflexiones sobre el principio de protección al trabajador y su influencia en el ámbito sustantivo y procesal del derecho laboral: Otra mirada al caso Kronos
}

\author{
Reflections about the principle of worker protection and its influence \\ on the substantive and procedural scope of labor law: \\ Another view at the Kronos case
}

\author{
Pablo Arellano Ortiz y Johann Benfeld Escobar \\ Pontificia Universidad Católica de Valparaíso, Chile
}

\begin{abstract}
RESUMEN Este trabajo busca precisar las particularidades del régimen de protección reforzado que caracteriza al derecho laboral en su dimensión sustantiva y procesal probatoria. Para realizar tal cometido, toma como punto de partida el conocido caso de tutela laboral Madrid con Sociedad de Profesionales Kronos. A partir del estudio de este caso, en el que las nuevas tecnologías y su aplicación en los entornos laborales se torna jurídicamente conflictiva, muestra la forma en que el principio de protección al trabajador extiende su ámbito de influencia tanto al derecho sustantivo como al laboral probatorio procesal. Respecto del primero, el régimen protector ampliado adquiere primacía frente a otros derechos mediante la tutela de las garantías constitucionales. Respecto al segundo (derecho procesal probatorio laboral), el principio opera como criterio de atenuación del principio rector de la sana crítica (la libre averiguación de la verdad de los hechos), lo que deja en evidencia que el legislador laboral ha tenido en consideración valores de naturaleza extraepistémica en el diseño del sistema probatorio laboral.
\end{abstract}

PALABRAS CLAVE Principio protector, prueba, sana crítica, nuevas tecnologías.

ABSTRACT This paper seeks to specify the particularities of the reinforced protection regime that characterizes labor law in its substantive and procedural dimension of probation. In order to carry out this task, it takes as its starting point the well-known case of Madrid v. Sociedad de Profesionales Kronos. Based on the study of this case, in which new technologies and their application in labor environments becomes legally conflictive, it shows how the principle of worker protection extends its scope of influence to 


\begin{abstract}
both substantive and labor law procedural. With respect to the first, the extended protective regime takes precedence over other rights through the protection of constitutional guarantees. Regarding the second (procedure of proof in labor law) the principle operates as a criterion of attenuation of the guiding principle of sound criticism (the free investigation of the truth of the facts), leaving in evidence that the labor legislator has taken into consideration values of an extra nature epistemic in the design of the labor probation system.
\end{abstract}

KEYWORDS Protective principle, proof, sound criticism, new technologies.

\title{
Introducción
}

El régimen de protección ampliado del derecho laboral a favor de la parte más débil de la relación contractual (el trabajador) tiene su origen en la Revolución Industrial (Gamonal, 2010: 35). Ésta, como se sabe, supuso cambios radicales en la forma de entender el trabajo y la relación entre los trabajadores y los empleadores, debido, en gran medida, a la incorporación de nuevos conocimientos y tecnologías puestas al servicio de la optimización de los procesos productivos, cuestión que, a su vez, implicó una mejora en los métodos de producción (eficiencia de los recursos) y un mayor control de los trabajadores (régimen disciplinar de la industria moderna). ${ }^{1}$ Existe, por ende, al menos desde los tiempos de la modernidad, un fuerte vínculo entre el avance de las tecnologías y el desarrollo del ámbito protector del derecho del trabajo.

Aunque muchas cosas han cambiado desde la Revolución Industrial, en estos tiempos postmodernos hay algo que no ha variado: la política de la optimización de los procesos productivos y el aseguramiento de métodos de control eficientes sobre los rendimientos esperados de los trabajadores. Por el contrario, hoy en día se han visto notoriamente exacerbados, sobre todo cuando se piensa, por ejemplo, en las exigencias de la globalización económica. En este escenario, el avance de las nuevas tecnologías de la información y del conocimiento (TIC) han supuesto, para emplear una expresión de Houellebecq, una ampliación del campo de batalla: hoy los trabajadores más que nunca se ven expuestos a sistemas de optimización productiva y con-

1. Foucault atribuye al siglo XVIII no sólo el nacimiento de la Revolución Industrial, sino también la autoría del saber disciplinar. En este sentido, en referencia al nuevo método de control y vigilancia (el panóptico benthamiano), escribe: «Es polivalente en sus aplicaciones; sirve para enmendar a los presos, pero también para curar a los enfermos, para instruir a los escolares, guardar a los locos, vigilar a los obreros, hacer trabajar a los mendigos y a los ociosos. Es un tipo de implantación de los cuerpos en el espacio, de distribución de los individuos unos en relación con los otros, de organización jerárquica, de disposición de los centros y de los canales de poder, de definición de sus instrumentos y de sus modos de intervención, que se puede utilizar en los hospitales, los talleres, las escuelas, las prisiones» (Foucault, 2008: 238). 
trol que hace un par de siglos atrás hubiesen sido impensables (Houellebecq, 1994). Así, por ejemplo, encontramos que hoy el trabajador ya no firma el libro de asistencia a su trabajo para constatar el inicio y el término de su jornada laboral: ahora existe un dispositivo en el cual se controla el cumplimiento de la jornada mediante la lectura de la huella digital. ${ }^{2}$ Su grado de precisión como mecanismo de control ha indudablemente aumentado y, a la vez, ha evitado los fraudes que antes se podían efectuar firmando la hoja completa de la semana.

Pero el uso de la tecnología como mecanismo de mejora de la actividad productiva no está exento de dificultades. Por lo mismo, el derecho laboral ha debido adaptarse a la nueva realidad e intentar a su vez mantener el estándar protector que lo caracteriza como rama del ordenamiento jurídico. Para ello, ha establecido ciertas restricciones. En materia de derecho del trabajo, las actuaciones del empleador se encuentran limitadas por el respeto a las garantías constitucionales de los trabajadores, en especial cuando afectan su intimidad, su vida privada o su honra, según se establece en el artículo 5 del Código el Trabajo. ${ }^{3}$ Esta norma, así como otras que se pueden encontrar en materia laboral, limita el uso de tecnologías dentro de las facultades propias del empleador. ${ }^{4}$

El presente ensayo, precisamente, reflexiona en torno a los nuevos desafíos y exigencias del derecho laboral frente a las modernas tecnologías, además de la forma en que ellas pueden afectar los derechos de los trabajadores. ${ }^{5}$ Para ello, nos serviremos en este trabajo de un caso bastante conocido como marco de estudio para intentar aportar una mirada distinta sobre el cruce entre el ámbito protector del derecho del trabajo y las tecnologías: el caso Madrid con Sociedad de Profesionales Kronos, ${ }^{6}$ conocido ampliamente como caso Kronos. ${ }^{7}$

A grandes rasgos, los hechos del caso Kronos son los siguientes: una trabajadora de apellido Madrid, quien efectuaba labores administrativas de inspección técnica de obras (ITO administrativo), fue despedida por su empleador por considerar que incurrió en un incumplimiento grave de las obligaciones del contrato al compartir información confidencial de la empresa a una persona ajena a la misma. La información fue compartida a través de un sistema de chateo denominado Messenger, al cual

2. Sobre el avance de las nuevas tecnologías y formas de trabajo, véase Barthélémy y Cette (2017).

3. Sobre esta norma y otras que ponen límites, véase Walker Errázuriz y Arellano Ortiz (2016).

4. Así se pueden citar, por ejemplo, los artículos 22, 154 bis y 485 del Código del Trabajo.

5. Un ejemplo de estos desafíos puede ser el uso de un escáner para el control de los trabajadores. Este problema se presentó ante los Tribuales del Trabajo chilenos en el caso Sindicato de Trabajadores de Empresa Socofar Logística con Socofar Logística Ltda., como registra la sentencia del Segundo Juzgado de Letras del Trabajo de Santiago, RIT T-320-2015, 27 de octubre de 2015.

6. Sentencia del Juzgado de Letras del Trabajo de Copiapó, RIT T-1-2008, dictada el 15 de septiembre de 2008.

7. Sobre este caso, véase Gamonal (2010: 44 y ss; 2015: 100 y ss) y Ferrada (2008). 
se puede acceder a través de la cuenta de correo electrónico Hotmail. La destinataria de la información era otra persona que desempañaba un puesto administrativo en la empresa Constructora Salfa, la cual estaba siendo fiscalizada por Kronos. La receptora de la comunicación con la señorita Madrid, además de poseer un vínculo de amistad, vivía con ella. El uso de Messenger en la empresa Kronos era conocido y tolerado. El jefe de la señorita Madrid, como señala en el juicio, encontró en un computador compartido una carpeta denominada «Mis loggs» dentro de la carpeta «Mis documentos»; en dicha carpeta se registró en forma involuntaria un respaldo de las discusiones entre la señorita Madrid y su amiga. Al revisar el contenido de los intercambios, se percató de que la señorita Madrid intercambió información que calificó de sensible y confidencial. Fue así cómo se enteró del intercambio que aludió como justificante para fundar el despido de la trabajadora.

El juicio versa entonces sobre si el empleador podía (o no) utilizar como fundamento para el despido de la trabajadora cierta información obtenida a partir de la lectura de un correo particular de la actora, enviado desde un computador de uso compartido de la empresa y alojado accidentalmente (por defecto) en una carpeta pública («Mis loggs»). Se trata, en consecuencia, de determinar, más allá de que la trabajadora pudiera haber cometido un acto reprochable, si el empleador puede vulnerar la esfera de la comunicación privada a través de un medio tecnológico, como es el contenido de un correo electrónico. El sentenciador lo grafica de la siguiente manera en el considerando octavo de la sentencia:

Luego de lo razonado, es ineludible que el objeto de este juicio es determinar si fue justificado el accionar del empleador en el ejercicio de sus facultades legales -leer el respaldo de una conversación privada y luego utilizarla públicamente- o si esta vulneración al trabajador - inviolabilidad de toda comunicación privada- no es aceptable amparado en sus derechos fundamentales, esto es, en aquellos derechos que por su trascendencia y jerarquía dentro del conjunto de los que son atribuidos a la persona, constituyen un núcleo central, esencial, que debe ser protegido de manera especial y fuerte frente al ataque de terceros.

En este trabajo, con todo, no intentamos hacer una nueva revisión sobre los fundamentos ocupados por el sentenciador en su examen de ponderación. Tampoco nos interesa cuestionar el uso de la tecnología, el correo electrónico, como algo problemático. De hecho, se parte de la base de que las nuevas formas de trabajo han incorporado los correos electrónicos como algo natural. Lo que nos interesa es demostrar que la sentencia se explica y justifica en virtud del principio de protección al trabajador que, como veremos más adelante, tiene la aptitud de desactivar otros principios generales de naturaleza sustantiva (deber de confidencialidad supuesto en virtud de la buena fe contractual) y procesal (principio de la averiguación material de la verdad en el sistema de la sana crítica como criterio de ponderación de la prueba judicial). En 
esta dirección, el caso Kronos nos demuestra varias cosas relevantes para el derecho laboral: i) cómo se pone en práctica la teoría de la exigibilidad horizontal de los derechos fundamentales y el principio protector. Además, a nuestro juicio, ii) nos sirve de caso de estudio para entender cómo la averiguación de la verdad de los hechos opera en una rama del derecho que está fuertemente influenciada por la protección de los derechos del trabajador.

Con el fin de desarrollar estas ideas, partiremos por enunciar el ámbito protector aplicable, para lo cual se describirá brevemente la concepción de los derechos fundamentales en el derecho del trabajo, y luego nos referiremos en específico al principio protector. Acto seguido, analizaremos cómo el principio de protección al trabajador extiende su ámbito de influencia en la ponderación de la prueba judicial, con lo que morigera de manera considerable el principio de la averiguación de la verdad material de los hechos como criterio fundamental para la recta aplicación del derecho.

\section{La esfera de la vida privada del trabajo: Derechos fundamentales y principio protector}

El sentenciador del caso Kronos llegó a la convicción de que ha existido una vulneración de derechos fundamentales, los cuales deben ser protegidos. En su considerando octavo, la sentencia indica:

Con lo razonado, este juez, como lo expresará en lo resolutivo, estima que el demandado no ha dado suficientes fundamentos de las medidas adoptadas y su proporcionalidad, por lo que necesariamente deberá instarse por la protección del derecho fundamental del trabajador, materializando con ello la tutela judicial efectiva del mandato contenido en el inciso primero del artículo quinto del Código del Trabajo, que ha dispuesto que el ejercicio de las facultades que la ley le reconoce al empleador tienen como límite el respeto a las garantías constitucionales de los trabajadores, en especial cuando pudieran afectar la intimidad, la vida privada o la honra de éstos. La norma citada viene a ser, sin duda, el correlato laboral del principio de vinculación directa, contenido en el inciso segundo del artículo sexto de nuestra Constitución Política de la República, el cual dispone que sus preceptos - entre ellos los derechos y garantías reconocidos- obligan tanto a titulares como integrantes de los órganos del Estado, como a toda persona, institución o grupo.

La teoría de la protección de ciertos derechos fundamentales de los trabajadores $^{8}$ tiene su origen en el caso Lüth de 1950. Éste, a su vez, permitió una evolución jurisprudencial y legal que, al día de hoy, sigue en expansión más allá del país que la vio nacer. En tal sentido, Chile también ha recogido la teoría alemana del triple efecto de los derechos fundamentales (Drittwirkung der grundrechte), sobre la

8. En esta materia hemos seguido lo expuesto en Walker Errázuriz y Arellano Ortiz (2016: 165-170). 
exigibilidad horizontal de derechos fundamentales, la cual tiene su origen en el referido caso. ${ }^{9}$

En este caso los hechos se pueden resumir de la siguiente manera: H. Lüth, presidente de la agencia de prensa de Hamburgo, hizo un llamado público a boicotear la última película de Veit Harlan, director de cine que, durante el periodo en que Hitler estuvo en el poder en Alemania, realizó una película de tendencia antisemita. Como reacción a este llamado a boicot, la productora cinematográfica demandó a Lüth, tras lo cual ganó en primera y segunda instancia argumentando que el boicot habría vulnerado las buenas costumbres. Posteriormente, Lüth recurrió al Tribunal Constitucional alemán afirmando que se le transgredió su libertad de expresión. El Tribunal Constitucional le dio lugar a lo solicitado por Lüth señalando que el tribunal civil no habría interpretado la ley al tenor de los derechos fundamentales, sin tomar en cuenta la dimensión objetiva de éstos dentro de un sistema jurídico, el cual incluye al derecho privado. Entonces se acogió la idea de que un particular puede solicitar el respeto de un derecho fundamental por otro particular, lo cual rompió la idea clásica de que la exigencia de estos derechos se hace solo al Estado. Esta jurisprudencia es, pues, la que marcó el inicio para que estos derechos puedan ser exigidos a otro particular. En un primer momento se trató de derecho civiles, pero luego esta teoría llegó al derecho del trabajo exigiendo derechos fundamentales laborales a otro particular.

La doctrina ha calificado el efecto emanando de esta jurisprudencia como de «eficacia» mediata o indirecta de los derechos fundamentales. Sin embargo, a nuestro parecer lo que importa verdaderamente es la exigibilidad de los derechos fundamentales, es decir, contra quién estos derechos son exigibles (Walker Errázuriz y Arellano Ortiz, 2016: 167).

Esta exigibilidad de los derechos fundamentales ha permitido a la doctrina chilena concluir que, en nuestro ordenamiento jurídico, existe una efectividad horizontal de estos derechos (Martínez Estay, 1998). Sin embargo, el profesor Gamonal ha sostenido que la exigibilidad en materia del derecho del trabajo debemos entenderla como diagonal (Gamonal, 2009: 72; 2015) y no de manera horizontal. No se trata de una exigibilidad vertical desde el particular al Estado ni tampoco complemente horizontal entre particulares. Esto porque la relación entre los sujetos del contrato de trabajo es asimétrica - uno ejerce poder sobre otro-, poder que no se puede comparar con el del Estado, pero que es suficiente para señalar que las partes, trabajador y empleador, no están en un plano de igualdad.

9. Jurisprudencia del caso Lüth, Corte Constitucional Alemana, BVerfGE 7, 198(205), decisión del 15 de enero de 1958. Sobre este tema, véase Favoreu y otros (2008: 861, 881), Jouanjan (1998: 44) y Gamonal (2008: 3 y ss). 
Ugarte (2009a: 3; 2011), siguiendo en esto a Palomeque, distingue, con el propósito de explicar el régimen de protección ampliado de ciertos derechos laborales, entre derechos específicos y no específicos. Así, para este autor existen:

- Derechos laborales propiamente tales, atribuidos al trabajador como contratante débil, que han permitido asegurar un mínimo socialmente aceptable para los trabajadores: salarios mínimos, jornada de trabajo, indemnizaciones por término de contrato.

- Derechos fundamentales específicos atribuidos al trabajador como miembro de una organización de representación de intereses, que han permitido al derecho del trabajo intentar democratizar la dirección económica y política de las empresas y de algún modo de la propia sociedad: libertad sindical, derecho negociación colectiva, huelga.

- Derechos fundamentales inespecíficos atribuidos al trabajador en su calidad de ciudadano, que han permitido al derecho del trabajo garantizar al interior de las empresas un trato digno y acorde con un miembro de una sociedad democrática: intimidad, integridad, libertad de expresión, no discriminación.

Gamonal, influenciado por las ideas de Américo Plá, ${ }^{10}$ afirma, por su parte, que la actividad protectora del derecho del trabajo, con todo, no se circunscribe únicamente a la protección de los derechos fundamentales propiamente tales, específicos y no específicos, de los trabajadores. Su esencia protectora también está basada en los principios fundantes de la rama. En este contexto, el concepto de principios, como indica el propio Plá, se traduce en la idea de

líneas directrices que informan algunas normas e inspiran directa o indirectamente una serie de soluciones, por lo que pueden servir para promover y encauzar la aprobación de nuevas normas, orientar la interpretación de la existentes y resolver los casos no previstos (Plá Rodríguez, 2015: 34).

En otras palabras, «principio de derecho del trabajo» es sinónimo de línea inspiradora de la base misma de sus normas, de sus ideas matrices.

Plá, en esta dirección, plantea los siguientes principios (Plá Rodríguez, 2015: 53):

- Principio protector, del cual se pueden concretar tres ideas: in dubio pro operario; regla de la aplicación de la norma más favorable; y regla de la condición más beneficiosa.

10. Profesor uruguayo, iniciador en la línea de la conceptualización y delimitación de los principios en derecho del trabajo. Es este autor el precursor a nivel latinoamericano de la conceptualización y clasificación de los principios en esta rama y quien además ha influenciado con sus ideas la doctrina laboralista chilena, tal como se ha señalado en Walker Errázuriz y Arellano Ortiz (2016: 98). 
- Principio de la irrenunciabilidad de los derechos.

- Principio de la continuidad de la relación laboral.

- Principio de la primacía de la realidad.

- Principio de la razonabilidad.

- Principio de la buena fe. ${ }^{11}$

Como hemos adelantado, en la doctrina nacional es el profesor Gamonal quien, a nuestro parecer, ha desarrollado de manera más importante en sus publicaciones los conceptos y teoría sobre los principios. ${ }^{12}$ Gamonal, en términos generales, distingue entre el «principio de protección» y el «principio de libertad sindical», el primero con múltiples expresiones y el segundo de gran trascendencia en materia de derecho colectivo, pero que no desarrollaremos en este trabajo.

Para este autor, el principio de protección establece que el derecho del trabajo tiene una clara vocación de tutela y protección de la parte más débil: el trabajador, y solo aplicable a favor del trabajador (Quiroz Domingo, 2014), ya que en las relaciones sociales se dan vínculos de poder y uno de los más intensos es probablemente el de las relaciones de trabajo. La idea matriz del derecho del trabajo es la protección del trabajador. De esta manera, el derecho del trabajo humaniza las relaciones laborales. Este principio estaría compuesto por el principio in dubio pro operario, el principio de la norma más favorable, el principio de la condición más beneficiosa, el de la irrenunciabilidad de los derechos, el de la continuidad o estabilidad laboral y el principio la primacía de la realidad. Veamos brevemente cada uno de los subprincipios.

El principio in dubio pro operario se utiliza siempre que no esté en pugna con la voluntad del legislador y posee dos manifestaciones: una legal y otra judicial. Existe un criterio de aplicación a favor del trabajador al momento de crear la ley y al momento de aplicarla: siempre se debe preferir la interpretación que esté a favor del trabajador. El principio de la norma más favorable consiste en que, para el caso en que exista más de una norma aplicable, se debe optar por aquélla que sea más favorable, aun cuando no hubiere correspondido de acuerdo con los criterios de jerarquía. El principio de la condición más beneficiosa implica que la aplicación de la norma del trabajo no debe servir para disminuir las condiciones más favorables en que pudiera encontrarse el trabajador. Se trata entonces de mantener las condiciones anteriores que le eran favorables al trabajador. La irrenunciabilidad de los derechos conlleva la

11. Estos principios fueron complementados por otros en la última edición de su libro; entre ellos, el de la no discriminación (Plá Rodríguez, 2015: 54).

12. No obstante, hay otros grupos de autores a nivel nacional que también han estudiado los principios de esta rama: Walker Érrazuriz y Arellano Ortiz (2016), Palomo Vélez (2006, 2007), Thayer Arteaga y Novoa Fuenzalida (2010), Humeres Magnan y Humeres Noguer (2009) y Lanata Fuenzalida (2010). 
imposibilidad jurídica de privarse de las ventajas entregadas por el derecho. Se trata entonces de poder mantener los beneficios mínimos establecidos por las leyes laborales. La continuidad o estabilidad laboral consiste en que el derecho del trabajo busca que las relaciones laborales sean estables. La estabilidad laboral se proyecta en tres facetas: en la tipología contractual, en el dinamismo contractual y en el término de la relación de trabajo. La primacía de la realidad implica que, ante posibles situaciones de abusos, se va a preferir lo que suceda en los hechos por sobre las formas, formalidades o las apariencias. Priman los hechos o la práctica por sobre lo que se consigna en los documentos.

El principio de la tutela o protección del trabajador puede considerarse como un criterio fundamental que orienta el derecho del trabajo ya que éste, en lugar de inspirarse en un propósito de igualdad, responde al objetivo de establecer un amparo preferente a una de las partes, el trabajador.

Mientras que en el derecho común constituye una preocupación constante para asegurar la paridad jurídica entre los contratantes, en el derecho laboral la preocupación esencial parece ser la de proteger a una de las partes para lograr que, a través de esa protección, se alcance una igualdad sustantiva y real entre ellas (Walker Errázuriz y Arellano Ortiz, 2016: 100).

Cabe preguntarse hoy si este principio continúa vigente, lo que da lugar, en otros términos, al dilema sobre si el trabajador necesita o no de protección normativa. Ello también significa que debe calibrarse la circunstancia de si el trabajador sigue siendo económicamente débil; si lo es, el principio de protección continúa vigente. El principio protector lleva también a analizar el carácter de la tutela protectora. Para el profesor Francisco Walker Linares, la tutela protectora del trabajador tiene siempre en vista mejorar la condición económica y social de los trabajadores de toda índole (Walker Linares, 1957: 8).

La actividad protectora del derecho del trabajo ha visto ampliado su campo de acción a raíz del reconocimiento de la protección de los derechos fundamentales inespecíficos, ya que los específicos constituyen su campo de protección natural. La esfera protectora, entonces, posee una amplitud que va más allá de las reglas o normas que se establezcan en códigos, leyes o reglamentos. Su fundamento es de una jerarquía superior. De hecho, la legislación del trabajo establece que el juez laboral puede apoyarse en los principios para fundamentar su decisión de acuerdo con lo que se establece en el artículo 459 número 5 del Código del Trabajo. ${ }^{13}$ De esta manera, los principios no resultan ser solamente parte del aspecto sustantivo a resolver.

13. Artículo 459 del Código del Trabajo: «La sentencia definitiva deberá contener: [...] 5) Los preceptos constitucionales, legales o los contenidos en tratados internacionales ratificados por Chile y que se encuentren vigentes, las consideraciones jurídicas y los principios de derecho o de equidad en que el fallo se funda». 
A nuestro entender, el principio protector resulta vital al momento de buscar un nexo hacia el derecho procesal. De acuerdo con el profesor Gamonal, la idea de protección también se puede encontrar en materia procesal laboral e incluso nos indica que existe una proyección en el ámbito laboral del principio sustantivo de protección del trabajador (Gamonal, 2015: 99-100). Sobre todo, estimamos que existe dicha proyección cuando el trabajador, como en el caso Kronos, se encuentra en una posición de desventaja al carecer de medios para que el empleador no entre al correo electrónico. Es el derecho procesal el que debe equilibrar las partes a través de una búsqueda de la verdad orientada a la protección del más débil.

Cabe tener presente que para el profesor Plá el derecho del trabajo, como toda rama jurídica, no debe ser estático. Esto debido a que se encuentra estrechamente ligado con la vida real y es sensible a las exigencias del mundo de los hechos (Plá Rodríguez, 2015: 70). De esta manera, nos afirma que los principios no son un obstáculo a los cambios de los tiempos. Todo lo contrario, «su propia maleabilidad les permite mantener la sustancia aunque cambie todo lo demás» (Plá Rodríguez, 2015: 71).

Es justamente esa maleabilidad la que resulta de interés para esta investigación. A nuestro entender, el juez, al momento de apreciar la prueba y luego decidir sobre el caso concreto, debe tomar en cuenta cómo el derecho del trabajo evoluciona, muta y cambia, pero a la vez conserva su base a través de los principios de la rama, en particular el principio protector. Es esta maleabilidad la que permite al juez llegar a una solución acorde con los fundamentos sustantivos de su jurisdicción especializada.

La maleabilidad de los principios permite, además, que se puedan adaptar a nuevas necesidades. En este sentido, el profesor Gamonal señala que el principio protector constituye la columna vertebral del ordenamiento protector y que le ha dado continuidad al mismo (Gamonal, 2013). Así, ante nuevas formas de trabajo en que las recientes tecnologías pueden afectar derechos fundamentales básicos de los trabajadores, los principios resultan ser un eje articulador de protección jurídica para ellos. De entre estos principios, el protector no solo inunda lo sustantivo, sino que también al ámbito procedimental.

\section{El estándar de valoración judicial propio del derecho del trabajo: La sana crítica dentro del derecho probatorio laboral}

Como recién hemos señalado, el principio de protección al trabajador no sólo permea el ámbito del derecho sustantivo laboral y le entrega una fisonomía propia, sino que su ámbito de influencia se extiende también a materias de naturaleza procesal. Entre ellas nos interesa particularmente la que se refiere al régimen de ponderación de la prueba judicial y la forma en que el principio de protección modela, de una manera bastante particular, el criterio del sentenciador al momento de valorar la prueba rendida en autos. A fin de hacer lo más clara posible nuestra exposición, comenzaremos 
diciendo algunas palabras generales sobre la sana crítica (el sistema de ponderación general elegido por el legislador laboral). El examen de determinadas características de este sistema de ponderación nos permitirá mostrar, en un segundo momento, que existe una disonancia entre el principio de averiguación de la verdad de los hechos como criterio esencial para la determinación del derecho y las particularidades que se verifican en el proceso laboral (que, a su vez, expresan la primacía del principio de protección al trabajador). Finalmente, mostraremos que la única forma de entender las particularidades del derecho probatorio laboral y su régimen de protección reforzado a favor del trabajador pasa necesariamente por comprender el ámbito de acción e influencia del principio de protección al trabajador.

El artículo 456 del Código del Trabajo dispone que

el tribunal apreciará la prueba conforme a las reglas de la sana crítica. Al hacerlo, el tribunal deberá expresar las razones jurídicas y las simplemente lógicas, científicas, técnicas o de experiencia, en cuya virtud les asigne valor o las desestime. En general, tomará en especial consideración la multiplicidad, gravedad, precisión, concordancia y conexión de las pruebas o antecedentes del proceso que utilice, de manera que el examen conduzca lógicamente a la conclusión que convence al sentenciador.

De acuerdo con esta disposición, al momento de valorar la prueba, el juez laboral debe adecuar su razonamiento a ciertos principios de la lógica (en esencia el de no contradicción), a las máximas de la experiencia ${ }^{14} \mathrm{y}$ a los conocimientos afianzados por la ciencia (probablemente los que sean proporcionados por peritos).

Desde el punto de vista conceptual, la sana crítica, en cuanto sistema de ponderación de la prueba, se inscribe dentro de los regímenes de valoración libre. En tal sentido, como lo ha afirmado Jordi Nieva:

Aquello que se deduce de la «sana crítica» no difiere en absoluto de lo que pretende la intime conviction o la freie Beweiswürdigung. Pudiendo concluir, llegados a este punto, que las iniciales enseñanzas de Beccaria y la liberación en la valoración de la prueba inspirada con gran difusión por Blackstone y Bentham, finalmente tuvieron bastante éxito en toda Europa, porque básicamente debió existir una voluntad co-

14. Para una aproximación clásica a la idea de «máximas de la experiencia», véase Stein (1893: 195). Este autor, específicamente en el apartado de las denominadas proposiciones empíricas, ensaya una definición de las máximas que ha llegado a ser canónica: «sie sind Definitionen oder hypotetische Urtheile allgemeinen Inhaltes, vom concreten in diesem Prozesse abzuurtheilenden Falle und seinen einzelnen Thatsachen unabhängig, aus der Erfahrung gewonnen, aber selbständig gegenüber den Einzel fallen, aus deren Beobachtung sie abgezogen sind, und über die hinaus sie für neue Fälle Geltung beanspruchen» («ellas son definiciones o juicios hipotéticos de contenido general, independientes del caso concreto que se juzga en el proceso, y de sus hechos individuales, obtenidos de la experiencia, pero independientemente del caso particular de cuya observación se sustraen, y más allá del cual se aplican a los nuevos casos»). Véase Stein (1893: 21-22). 
mún en los juristas de aquel tiempo: la utilización de la racionalidad inspirada muy probablemente por las obras de la Ilustración, y el abandono de una valoración de la prueba que sólo tenía en cuenta, no la realidad de los hechos, sino la autoridad de las leyes y autores antiguos, siendo víctima, con ello, de la peor interpretación - aunque también la más simple- que pudo hacerse del método escolástico (Nieva, 2010: 8990).

La sana crítica es entendida, así, como una variante de los sistemas de libre ponderación de la prueba. En éstos, el centro de la actividad probatoria está puesto en la averiguación de la verdad de los hechos y, por idéntica razón, en la racionalidad de los métodos incorporados con tal propósito en el procedimiento judicial. La idea fundamental en este tipo de régimen probatorio es

que el ciudadano tiene derecho a demostrar la verdad de los hechos en los que funda su pretensión procesal. En otras palabras, el ciudadano tiene derecho a probar que se han producido, o no, los hechos a los que el derecho vincula consecuencias jurídicas. Sólo de este modo puede garantizarse una correcta aplicación del derecho y, como argumentaré más adelante, una adecuada seguridad jurídica (Ferrer, 2007: 54).

Con todo, la adopción del sistema de ponderación de la sana crítica en el proceso laboral chileno deja abierta una cantidad considerable de cuestiones teóricas y prácticas. Dentro de ellas, por una parte, está el problema de la falta de precisión de las ideas estructurales del concepto mismo de «sana crítica» (principios de la lógica, máximas de la experiencia y conocimientos científicamente afianzados); por otra, se encuentra la falta de determinación del estándar probatorio, es decir, las ausencia de un criterio de suficiencia en virtud del cual el sentenciador dé por acreditados los hechos contenidos en las proposiciones asertivas de las partes (empleador-trabajador) y, aún por otra, pero conexa con la anterior, la posición que ha de adoptar el juez frente a la eventual colisión de valores epistémicos y extraepistémicos involucrados en la fase de valoración y suficiencia de la prueba.

De alguna forma, algunas de estas cuestiones han sido intuitivamente resueltas por los tribunales laborales, en cuanto ellos han entendido que en materias de su jurisdicción, aun cuando se ha optado por un sistema de ponderación libre de la prueba, que en teoría busca la averiguación de la verdad de los hechos, dicha valoración es siempre modelada, necesariamente, por ciertos principios sustantivos de la rama (en virtud de que el legislador no ha fijado con autoridad el estándar de prueba) que resuelven tanto la cuestión del estándar probatorio como la de la colisión de valores epistémicos y no epistémicos implicados en el proceso laboral.

Esta situación se advierte con total claridad en el caso Kronos. En efecto, al restar valor probatorio en este juicio a la información contenida en una comunicación particular de la trabajadora, en razón de que dicha información quedaría protegida por la garantía constitucional de inviolabilidad de todo tipo de comunicación privada 
consagrada en el artículo 19 número 5, la decisión del tribunal evidencia una toma de posición frente a las cuestiones vinculadas con el estándar probatorio, los principios que lo inspiran y los medios idóneos para la satisfacción de los mismos.

Probablemente, el uso de las nuevas tecnologías en los ambientes laborales incremente la ocurrencia de casos similares al de Kronos. Los escenarios posibles en este contexto son muy variados: el uso compartido de redes de trabajo, los espacios virtuales comunes dentro de una «nube», el dominio sobre recursos virtuales en dispositivos compartido (hardware y software), etcétera. En todos estos casos, y otros muchos que dejamos a la imaginación del lector, la cuestión a resolver para la prueba de los hechos dentro de un litigio laboral será la legitimidad de excluir o minusvalorar ciertos medios probatorios cuando éstos vulneren ciertas garantías fundamentales del trabajador.

Ahora bien, y de acuerdo con lo que venimos diciendo, la idea de «excluir» $\mathrm{O}$ «minusvalorar» algunos medios probatorios por razones extraepistémicas (aun cuando se fundamente en la protección de garantías fundamentales del trabajador) no resulta necesariamente congenial con un sistema de libre ponderación de la prueba (como la «sana crítica»). De hecho, dentro del ámbito de la epistemología jurídica, uno de los elementos más resistido por los teóricos es la existencia de ciertas reglas (o compromisos) de exclusión o disminución de la ponderación de la prueba, en tanto esas estrategias no guarden una relación directa con la averiguación material de la verdad. ${ }^{15}$

En efecto, los llamados sistemas racionales de ponderación de la prueba, caracterizados por circunscribir el derecho probatorio dentro de la categoría más general del «debido proceso», garantizan a las partes litigantes el derecho a utilizar todos los medios de prueba disponibles a fin de probar la verdad de sus alegaciones, de forma inmediata dentro del proceso y ante un juez que ha de ponderar la prueba de manera racional (mediante los métodos idóneos de la epistemología general) y jurídica.

En tal dirección, Michele Taruffo ha señalado que

según la opinión dominante, el derecho a presentar todas las pruebas relevantes es parte esencial de las garantías generales sobre la protección judicial de los derechos y del derecho de defensa, pues la oportunidad de probar los hechos que apoyan las pretensiones de una de las partes es condición necesaria de la efectividad de tales garantías (Taruffo, 2010: 56).

En este contexto,

la valoración de la prueba tiene por objeto establecer la conexión final entre los medios de prueba presentados y la verdad o falsedad de los enunciados sobre los

15. Esta tradición es en gran medida, aunque no exclusivamente, tributaria de la obra de Jeremy Bentham. Para una aproximación sobre el particular, véase de este autor: Bentham $(1825 ; 1843)$. 
hechos en litigio. La valoración pretende establecer si las pruebas disponibles para el juzgador apoyan alguna conclusión sobre el estatus epistémico final de los enunciados (Taruffo, 2010: 131).

William Twining, por su parte, en Rethinking evidence, nos entrega un listado de nueve características propias de lo que él denomina la tradición racional de la valoración de la prueba (rational theories of evidence and proof: some common assumptions). Resumiendo mucho las cosas, estas reglas son: la convicción de que el conocimiento de los hechos pasados es posible; el establecimiento de la verdad material de los hechos (dentro de un proceso) es la condición necesaria para la justicia del caso particular; existe una comunión necesaria y racional entre la verdad de los hechos y la decisión justa (en el derecho vigente); a falta de juicios absolutos en materia de hechos a probar, ha de recurrirse al cálculo de probabilidades; el uso instrumental del cálculo de probabilidades debe ser realizado en términos racionales (justificados); las probabilidades han de interpretarse siempre en términos de natural ocurrencia de los hechos (sentido común) y de acuerdo al estado actual de la ciencia; en materia probatoria, la búsqueda de la verdad debe tener prioridad frente a otros fines del proceso (seguridad del Estado, el orden de las familias, la protección de garantías individuales, etcétera); la evaluación de las reglas probatorias y de procedimiento probatorio han de juzgarse por su eficacia en la obtención de la verdad más que en otros criterios y valores disponibles en el sistema (celeridad, economía, etcétera); la psicología forense y la ciencia del procedimiento deben esforzarse en proveer a los operadores jurídicos (sobre todo al juez) métodos fiables para la búsqueda de la verdad de los hechos. ${ }^{16}$

Por lo menos dos de las características precedentes (propias de la tradición racional y vinculadas a la idea de «sana crítica») son relevantes para el análisis del caso Kronos: primero, la prioridad teórica, en materia de derecho probatorio, de la búsqueda de la verdad frente a otros fines del derecho y, segundo, el criterio de evaluación epistemológica de las reglas y procedimientos probatorios (nuevamente la verdad sobre otros cánones: celeridad, economía, oportunidad, etcétera). ${ }^{17}$

16. Sobre este punto, véase Twining (2017: 76).

17. Por cierto, desde una perspectiva estrictamente epistemológica, la exclusión de prueba o la minusvaloración de la misma por criterios metacognitivos es bastante problemática y discutible. De hecho, Larry Laudan, al reflexionar sobre el procedimiento probatorio penal norteamericano, dedica el capítulo nueve de su conocido libro Verdad, error y proceso penal a discutir sobre la legitimidad de introducir, a propósito del derecho probatorio, «otros valores» de carácter no epistémico. Al respecto escribe: «He sugerido alternativas a esas reglas que podrían ser más favorables para la averiguación de la verdad sobre los hechos delictivos. Ahora, al final de este largo experimento mental, debemos elegir entre esas reglas que promueven genuinamente la búsqueda de la verdad y sus homólogas que la obstaculizan. Si los valores epistémicos fuesen los únicos valores en juego, sería previsible la elección. Pero otros valores interfieren - desde los derechos que se atribuyen a las partes de un proceso penal hasta cuestiones de imagen pública y eficiencia-, por lo que deben tomarse decisiones difíciles». Véase Laudan (2013: 291-292). 
Pues bien, en el caso Kronos, la cuestión a dilucidar en la especie, como sabemos, era si la información obtenida a partir de la lectura «accidental» de una comunicación particular vía Messenger de una trabajadora podía ser «usada» por el empleador para despedirla legítimamente, por haber infringido aquélla las disposiciones de confidencialidad aceptadas en el contrato.

En la secuela del proceso varios hechos fueron acreditados (no se trata, por cierto, de todos los hechos, sino de los que nos interesa destacar): i) efectivamente existió una comunicación entre ambas empleadas, en la cual se comentaban algunos aspectos relacionados con la fiscalización de Kronos a Salfa; ii) a la información contenida en el correo particular se llegó de forma casual (no se pudo acreditar otra cosa), al archivarse de manera automática en una carpeta del computador de uso común de la empresa dicha información; iii) que si bien existía un «Instructivo de la Empresa Kronos» que regulaba el uso de los computadores comunes y los limitaba exclusivamente a cuestiones relacionadas con el trabajo, la práctica habitual de los trabajadores de Kronos, en lo que a dichos computadores toca, era muy diferente (en general los usaban también para fines particulares sin que nadie exigiera lo contrario); iv) que de la prueba rendida en autos resulta evidente que el correo enviado por la trabajadora tenía un carácter personal, dirigido en especial a un destinatario particular y sin intención de que su contenido fuese conocido por terceras personas; finalmente, v) de forma muy interesante, el tribunal señala:

Se encuentra asentado con la prueba rendida, que ni en el contrato de trabajo ni en el reglamento de orden, higiene y seguridad de la empresa, existe una regulación expresa del uso de los medios tecnológicos - computadores y recursos que proporciona internet e intranet-, ni tampoco existe una regulación o procedimiento para la revisión de la información almacenada en los computadores que sean de carácter privado de los usuarios; en ese entendido, no existe prohibición alguna relativa a guardar información privada en una carpeta del computador, ni menos una norma que autorice a revisar esa información privada o a invocarla para establecer una sanción. Por el contrario, sí queda asentado que en dicho reglamento, dentro de las obligaciones del trabajador, está el respetar a la empresa y a sus representantes, en su persona y dignidad, actuando en todo momento con la debida lealtad. Considerándose infracciones a este deber el transmitir o traspasar a otras empresas del rubro informaciones de carácter privado de la empresa. Asimismo, que dentro de las prohibiciones del trabajador no se contempla ninguna relativa al asunto debatido y que en un ítem denominado "Confidencialidad» se señala que toda la información, ya sea de propiedad de la empresa o de sus clientes, que entregue Kronos a su personal para el desarrollo de sus funciones, así como también aquella información que se genere durante el desarrollo de los servicios es confidencial, por lo que no podrá ser entregada a terceros, ya sea en papel o en medios magnéticos, sin la autorización de la administración de Kronos o del representante del cliente. Por último, en el ítem de «Sanciones y amonestaciones» se contempla que las sanciones asociadas a las 
infracciones de las normas referidas son la amonestación; siendo la terminación del contrato una decisión que depende de la gravedad, poniéndose como ejemplo la falta de lealtad a la empresa en cualquier circunstancia.

Comentando esta sentencia, Juan Carlos Ferrada ha señalado de buena manera que, aunque no comparte el elaborado razonamiento del sentenciador, el resultado es el adecuado conforme a la legislación vigente, toda vez que en el caso Kronos,

el empleador no tenía fundamento constitucional o legal alguno para interceptar, abrir o registrar la comunicación privada, lo que llevaría necesariamente a sostener la inconstitucionalidad de la medida por vulneración del artículo 19 número 5 de la Constitución Política de la República, ya sea por aplicación directa de este precepto o, por vía indirecta, constatando la inconstitucionalidad de la aplicación de la causal de despido, fundada en una conducta irregular como base para aplicar éste (Ferrada, 2008: 271).

Sin embargo, sin advertirlo, tanto Ferrada como el tribunal coinciden en un aspecto que, para fines de este trabajo, es importante. En efecto, la cuestión en este caso no consiste precisamente en la averiguación de ciertos hechos con el propósito acoger una de las pretensiones en competencia. En otras palabras, la cuestión no es tanto si «el contenido» de la comunicación efectivamente constituía una infracción a una obligación de confidencialidad sobre cierta información sensible para el proceso de fiscalización de una de las empresas, sino si la obtención de la misma vulnera cierta garantía constitucional o, como piensa el tribunal, hace necesario un juicio de ponderación de los derechos o intereses en juego (privacidad/confidencialidad). El problema, si bien se lo piensa, no es de naturaleza epistemológica, no está en juego solo la averiguación de la verdad, sino que se trata de un problema axiológico, un problema sobre la determinación del peso relativo de ciertos valores indisolublemente imbricados en la fase probatoria: el principio de protección al trabajador, el régimen de tutela efectiva de los derechos fundamentales, el diferente estándar exigido a una y otra parte a fin de dar por acreditados lo hechos, etcétera.

En este sentido, ya lo hemos adelantado, Laudan cuestiona en materia penal la legitimidad y conveniencia epistemológica de introducir en el diseño del régimen probatorio consideraciones de naturaleza extraepistémica. Así, cuando exista una colisión entre las reglas probatorias de contenido epistemológico y ciertos derechos personales de los involucrados en un proceso (generalmente garantías constitucionales), afirma Laudan, en un régimen de ponderación libre de la prueba, ha de estarse a la verdadera averiguación de los hechos y no a otros criterios. Según él, la vulneración de otros derechos o garantías constitucionales debe ser protegida mediante otros mecanismos jurídicos y procedimientos.

En materia laboral, nos parece, el asunto es aún más evidente e interesante. Pues aquí no sólo estamos en presencia de ciertas «reglas» de exclusión de prueba (como 
ocurre en materia penal), sino de verdaderos principios que modulan desde el inicio hasta el final la fase probatoria (protección). De no ser así, la sentencia del caso Kronos debiese haber avanzado en otra dirección: si el contenido del correo realmente constituyó una infracción a la obligación contractual de confidencialidad en virtud de su materia (información sensible de la empresa fiscalizadora y provechosa para la empresa fiscalizada), el tribunal debió haber rechazado la demanda, sin perjuicio de dejar a salvo otras acciones de naturaleza civil o penal en favor de la actora en razón de haber sido afectada en uno de sus derechos fundamentales.

De alguna forma, lo que venimos diciendo ha sido captado en buenos términos por Alex Stein, quien dedica prácticamente todo el cuarto capítulo de su Foundations of evidence a mostrar los inconvenientes del modelo probatorio epistemológico puro (es decir, uno que considera que el valor supremo en la fase de ponderación de la prueba judicial es el de la verdad). Aunque Stein centra su crítica en la falta de consideración del modelo epistemológico puro de lo que él llama «reglas de reparto o distribución de error» (con un marcado carácter político-moral), es decir, en las opciones político-morales que determinan, entre otras cosas, los diversos estándares probatorios, las exclusiones de prueba, etcétera, en el fondo pone de manifiesto que en los procesos judiciales se juega algo más que la mera búsqueda de la verdad de los hechos. ${ }^{18}$

Cuando se analiza el fallo de Kronos y el comentario que de él realiza, por ejemplo, Ferrada, se advierte que, en nuestro sistema, ni el legislador laboral ni los órganos jurisdiccionales encargados de aplicar el derecho vigente ni la doctrina especializada estarían con Laudan en este punto. Eso sí, en nuestro modelo procesal regulatorio de la prueba no está en juego tanto una discusión político-moral sobre las estrategias normativas para una mejor distribución del error en un sistema de prueba de ponderación libre, sino algo más complejo: la opción deliberada por un régimen protector reforzado de ciertas garantías fundamentales a favor del trabajador, justificado, principalmente, por un principio rector del derecho laboral: el principio de protección al trabajador que, llegado el caso, junto con modelar el estándar de prueba, tiene la aptitud de desactivar los principios propios del derecho probatorio afirmado por la tradición racionalista de la prueba (la verdad de los hechos).

Respecto a lo primero, esto es, la existencia de un régimen protector reforzado a favor del trabajador, Ugarte, a propósito del procedimiento de tutela laboral, ha señalado que en éste

no existe sólo una técnica de aligeramiento probatorio, sino varias modalidades distintas que, sin embargo, sirven a un mismo objetivo: facilitar la posición probato-

18. Sobre este punto, véase Stein (2005: 107-140). En contra de la crítica de Stein, véase Ferrer (2007: 81-86). 
ria por la vía de aligerar el esfuerzo probatorio del trabajador denunciante, atemperando, en algunos casos, los efectos del axioma central en la materia de que corresponde probar un hecho a quien lo alega (carga de la prueba formal), o modificando, en otros, el hecho de que el costo por la falta de certeza plena en la acreditación de un hecho debe soportarlo aquel que lo afirma (carga de la prueba material) (Ugarte, 2009b: 218).

Comentando en parte las ideas de Ugarte, Jorge Larroucau ha advertido, a su vez, de manera lúcida, que en el juicio de tutela laboral por violación de derechos fundamentales no laborales o inespecíficos,

el actor únicamente debe aportar una «chispa» de prueba para que se acoja su relato («de los antecedentes aportados por la parte denunciante resulten indicios suficientes», artículo 493 del Código del Trabajo), de modo que una vez que se despierta en el tribunal la «sospecha razonable» de que han ocurrido los hechos tal como el ha relatado el juez laboral está autorizado para acoger su demanda inmunizándolo de los errores en el veredicto. No dudo de que pueda haber buenas razones para repartir así los riesgos en materia laboral, pero lo que ahora me interesa remarcar es que ese estándar de prueba responde a la lógica continental de los beneficios («acoger los reclamos de atentados a ciertos derechos fundamentales del trabajador»), sin preocuparse de justificar el reparto de costos que conlleva («ipor qué debemos cargar a los empleadores con los gastos de una sentencia errónea?») (Larroucau, 2012: 788).

Es precisamente lo que ocurre en el caso Kronos. Así las cosas, la cuestión a resolver en este caso ( $y$ otros de similar naturaleza) es qué razones ha tenido el legislador laboral (y los tribunales en su interpretación del derecho) para alterar de tal modo el régimen probatorio teóricamente congenial con un sistema de libre valuación de la prueba.

Recientemente, y muy en concordancia con lo que venimos diciendo en este pequeño trabajo, Alejandra Aguilar ha aportado algunas ideas que pueden ayudar a comprender la lógica tras el régimen reforzado de protección que contempla la tutela laboral. Según Aguilar, el legislador laboral nacional ha efectuado una opción deliberada en orden a construir un modelo probatorio que toma como punto de partida el principio de protección al trabajador (artículo 19 número 6 de la Constitución Política). Es este principio el que explicaría, entre otras cosas, por qué razón cierta información que puede ser relevante en términos epistemológicos resulta naturalmente excluida en los procedimientos laborales (por ejemplo, en la vulneración de ciertas garantías constitucionales de la parte más débil del contrato). Pero, además, y relacionado con lo anterior, el principio de protección al trabajador también explicaría la existencia, en el ámbito del procedimiento laboral, de un estándar probatorio propio (diverso del derecho procesal penal y procesal civil), cuya principal característica sería incrementar las exigencias probatorias para el empleador y disminuirlas para el trabajador. Este régimen de protección se explicaría, entre otras razones, porque 
las partes contratantes en materia laboral son distintas y están en una situación de desigualdad, lo que se plasma en que la escrituración del contrato es de iniciativa del empleador, el acuerdo contractual no cuenta con mucho margen (o casi nulo) de negociación para el trabajador, el control y acceso de un eventual medio de prueba beneficia al empleador, [por lo que] tenemos razones suficientes para justificar que la exigibilidad en materia probatoria será superior respecto del empleador que del trabajador (Aguilar, 2016: 23).

\section{Reflexiones finales}

Así las cosas, el caso Kronos, a nuestro juicio, pone en evidencia que aunque el sistema de ponderación general de la prueba en materia laboral es el de la "sana crítica», en su régimen probatorio existen ciertas características exorbitantes a los sistemas de valuación libre de la prueba. Estas características propias, a su vez, se explican y entienden a partir de ciertos principios sustantivos del derecho del trabajo. En el caso Kronos, el principio de protección al trabajador posee sin duda un valor superior al momento de decidir el asunto. Este principio, nos parece, no sólo modela o morigera la valuación de la prueba (al excluir o minusvalorar cierta información relevante), sino también determina el estándar de prueba aplicable en este campo del derecho. Es cierto que en teoría se distinguen varias fases a propósito de la prueba (admisión, diligenciamiento, ponderación y fundamentación); sin embargo, a nuestro juicio, resulta contraintuitivo pensar que los órganos jurisdiccionales razonan en materia probatoria de forma discontinua, considerando las diferentes etapas como espacios estancos. Por el contrario, lo que demuestra el juicio de tutela laboral es que el principio de protección al trabajador irradia el procedimiento de inicio a fin; cuestión que afecta, como lo hemos demostrado, a la prueba de los hechos.

Ahora bien, las implicancias del caso Kronos no deben ser estudiadas como un fenómeno particular y transitorio. Compartimos, en este sentido, lo señalado por el profesor Gamonal hace un tiempo:

Sin lugar a dudas, las nuevas tecnologías, la estabilidad laboral y el desarrollo económico representan desafíos políticos enormes para las sociedades latinoamericanas, donde en forma clara el derecho del trabajo jugará un rol de trascendencia en los próximos años. Cabe esperar un debate de fondo y más serio en la materia (Gamonal, 2010: 48).

Ya no se cuestiona que los procesos tecnológicos afectan al trabajo mediante la ocupación, cada vez más común, de nuevas tecnologías puestas al servicio de los procesos productivos. Estas zonas de contacto, por el contrario, se seguirán produciendo y serán cada vez más diversas e intensas. Basta con observar las polémicas actuales con relación a la aplicación Uber (Barthélémy y Cette, 2017). De manera tal que no 
sólo es esperable que el uso y abuso de nuevas tecnologías en algún momento invada derechos fundamentales de los trabajadores, derechos que son protegidos, tal como lo demuestra el caso Kronos, por la legislación sustantiva bajo un estándar probatorio protector especial. He aquí lo relevante de tener un estándar probatorio que permita una cierta coordinación o conexión entre lo sustantivo y lo procedimental.

Finalmente, sólo cabe constatar que los procesos de producción se complejizan cada vez más y no puede hacerse caso omiso a sus implicancias dogmáticas y procesales. La discusión de la gig economy y de la uberización de la economía (Barthélémy y Cette, 2017) sin lugar a duda llevará a una discusión acerca de los alcances del principio protector y sobre su estándar probatorio. El caso Kronos, en definitiva, nos ilustra sobre las bases actuales en nuestro país de una discusión jurídica que pondrá en campos opuestos al principio protector del trabajo y a las nuevas tecnologías.

\section{Referencias}

Aguilar, Alejandra (2016). «Aproximación a una noción conceptual del estándar de prueba en el procedimiento laboral chileno». Revista de Derecho Laboral y Seguridad Social, 6 (1).

BARThÉLÉMY, Jacques y Gilbert Cette (2017). Travailler au XXIe siècle. L'ubérisation de léconomie? París: Odile Jacob.

Bentham, Jeremy (1825). A treatise on judicial evidence. Editado por Etienne Dumont. Londres: Baldwin, Craddock and Joy.

-. (1843). The works of Jeremy Bentham. Editado por John Bowling. Vol. 2, Principles of judicial procedure, with the outlines of a procedure code; Vol. 6, Introductory view of the rationale of evidence. Edimburgo: Simpkin, Marechal \& Co.

Favoreu, Louis, Patrick GaïA, Richard Ghevontian, Jean-Louis Mestre, Otto Pfersmann, Guy Scoffoni y André Roux (2008). Droit constitutionnel. 11. a ed. París: Dalloz.

FerradA, Juan Carlos (2008). «Abriendo camino en la tutela de derechos fundamentales en materia laboral: Buenas intenciones, malos instrumentos (Juzgado de Letras del Trabajo de Copiapó)». Revista de Derecho de Valdivia, 21 (2): 251-271. DOI: 10.4067/So718-09502008000200010.

Ferrer, Jordi (2007). La valoración racional de la prueba. Madrid: Marcial Pons.

Foucault, Michel (2008). Vigilar y castigar. Trad. de Aurelio Garzón del Camino. 2. ${ }^{a}$ ed. Buenos Aires: Siglo XXI.

Gamonal, Sergio (2008). El procedimiento de tutela de derechos laborales. $3 .^{\mathrm{a}}$ ed. Santiago: Legal Publishing.

-. (2009). «Procedimientos de tutela y eficacia diagonal de los derechos fundamentales». Revista Laboral Chilena, 11: 72-76.

-. (2010). Trabajo y derecho. Santiago: Abeledo Perrot / Legal Publishing. 
-. (2013). «El principio de protección del trabajador en la Constitución chilena». Estudios Constitucionales, 11 (1): 425-458. DOI: 10.4067/So718-52002013000100011.

-. (2015). La eficacia diagonal u oblicua y los estándares de conducta en el derecho del trabajo. Santiago: Thomson Reuters.

HouellebecQ, Michel (1994). Extension du domaine de la lutte. París: Maurice Nadeau.

Humeres Magnan, Héctor y Héctor Humeres Noguer (2009). Derecho del trabajo $y$ de la seguridad social. 18. a ed. Santiago: Jurídica.

JouANJAN, Olivier (1998). «La théorie allemande des droits fondamentaux». L'Actualité Juridique, Droit Administratif, 1998: 44-51.

Lanata Fuenzalida, Gabriela (2010). Contrato individual de trabajo. Santiago: Legal Publishing.

Larroucau, Jorge (2012). «Hacia un estándar de prueba civil». Revista Chilena de Derecho, 39 (3): 783-808. DOI: 10.4067/So718-34372012000300008.

Laudan, Larry (2013). Verdad, error y proceso penal. Madrid: Marcial Pons.

Martínez EstaY, José Ignacio (1998). «Los particulares como sujetos pasivos de los derechos fundamentales: La doctrina del efecto horizontal de los derechos». Revista Chilena de Derecho, 25 (1): 59-64. Disponible en http://bit.ly/2wIemu5.

Nieva, Jordi (2010). La valoración de la prueba. Madrid: Marcial Pons.

Palomo Vélez, Rodrigo (2006). «Los principios del derecho del trabajo: Cuestiones de la teoría tradicional y planteamiento de nuevos problemas». Revista Laboral Chilena, 147: 48-55.

-. (2007). «El rol de los principios en la aplicación del derecho del trabajo: Antecedentes conceptuales sobre el estado del arte en Chile». Revista Laboral Chilena, 11: 59-69.

Plá Rodríguez, Américo (2015). Los principios del derecho del trabajo. Clásicos Jurídicos Uruguayos, editado por Hugo Barreto Ghione. Montevideo: Fundación de Cultura Universitaria.

Quiroz Domingo, Felipe (2014). «Las manifestaciones del principio protector laboral sólo son aplicables en beneficio del trabajador». Derecho y Justicia, 4: 139-147. Disponible en http://bit.ly/2yTBaYB.

Stein, Alex (2005). Foundations of evidence. Nueva York: Oxford University Press.

STEIN, Friedrich (1893). Das private Wissen des Richters. Leipzig: C. L. Hirschfeld.

Taruffo, Michele (2010). La prueba. Madrid: Marcial Pons.

Thayer Arteaga, William y Patricio Novoa Fuenzalida (2010). Manual de derecho del trabajo. T. 4. Santiago: Jurídica.

Twining, William (2017). Rethinking evidence. Londres: Cambridge University Press. Ugarte, José Luis (2009a). Tutela de derechos fundamentales del trabajador. Santiago: Legal Publishing.

-. (2009B). «Tutela laboral de derechos fundamentales y carga de la prueba». Revista 
de Derecho de la Pontificia Universidad Católica de Valparaíso, 33: 215-228. DOI: 10.4067/So718-68512009000200005.

- (2011). Derechos, trabajo y privacidad. Santiago: Legal Publishing.

Walker Errázuriz, Francisco y Pablo Arellano Ortiz (2016). Derecho de las relaciones laborales. T. 1, Derecho individual del trabajo. Santiago: Librotecnia.

WALKer Linares, Francisco (1957). Nociones elementales de derecho del trabajo. Santiago: Nascimento.

\section{Reconocimiento}

Este trabajo presenta resultados del proyecto Fondecyt de iniciación núm.11.160.046, titulado: «Formulación de un concepto jurídico alternativo de reglas de sana crítica en materia probatoria y sistematización de los criterios y de las reglas particulares a él asociadas», en el que el profesor Benfeld es investigador responsable.

\section{Sobre los autores}

Pablo Arellano Ortiz es abogado. Doctor en Derecho por la Université de París Ouest Nanterre La Défense, Francia; profesor de Derecho del Trabajo y Seguridad Social, Pontificia Universidad Católica de Valparaíso. Correo electrónico pablo.arellano@pucv.cl.

Johann S. Benfeld E. es abogado. Doctor en Derecho por la Universidad de Salamanca, España; profesor de Filosofía y Teoría del Derecho, Pontificia Universidad Católica de Valparaíso. Correo electrónico: johann.benfeld@pucv.cl. 


\title{
REVISTA CHILENA DE DERECHO Y TECNOLOGÍA
}

La Revista de Chilena de Derecho y Tecnología es una publicación académica semestral del Centro de Estudios en Derecho Informático de la Facultad de Derecho de la Universidad de Chile, que tiene por objeto difundir en la comunidad jurídica los elementos necesarios para analizar y comprender los alcances y efectos que el desarrollo tecnológico y cultural han producido en la sociedad, especialmente su impacto en la ciencia jurídica.

\author{
EDITOR GENERAL \\ Daniel Álvarez Valenzuela \\ (dalvarez@derecho.uchile.cl) \\ SITIO WEB \\ rchdt.uchile.cl \\ CORREO ELECTRÓNICO \\ rchdt@derecho.uchile.cl \\ LICENCIA DE ESTE ARTÍ́CULO \\ Creative Commons Atribución Compartir Igual 4.0 Internacional
}

\begin{abstract}
y
La edición de textos, el diseño editorial

y la conversión a formatos electrónicos de este artículo

estuvieron a cargo de Tipográfica

(www.tipografica.cl).
\end{abstract}

